\title{
Oncologists' opinions on genetic testing for breast and ovarian cancer
}

\author{
Julie O. Culver, $M S^{1}$, Judy L. Hull, $M S^{2}$, Deborah F.B. Dunne, $M S^{3}$, and Wylie Burke, $M D, P h D^{4}$
}

\begin{abstract}
Purpose: To determine oncologists' practices and beliefs about genetic testing for hereditary breast and ovarian cancer and the extent to which oncologists are utilizing clinical genetics services. Methods: A survey was mailed to oncologists who treat adult patients in Washington, Oregon, Idaho, or Alaska. Results: Most oncologists (79\%) had discussed genetic tests with their patients, and $76 \%$ indicated they would like patients considering genetic testing to consult with a genetic counselor. Yet few (19\%) indicated their medical practice had the necessary services and staff to offer genetic testing, and only $11 \%$ had made referrals to medical genetics or genetic counselors. Conclusion: Most respondents support the use of genetic services, but few have made referrals to genetic counselors. Increased communication between oncologists and genetic counselors may enhance collaboration between these two disciplines. Genetics in Medicine, 2001:3(2):120-125.
\end{abstract}

Key Words: genetic counseling, disease susceptibility, genetic screening, BRCA1, BRCA2, survey, oncologists

Genetic testing for the hereditary breast cancer genes $B R C A 1$ and $B R C A 2$ is still relatively new, with clinical testing becoming available only within the past 5 years. Such testing has been the subject of much debate. Several studies have shown high levels of interest in genetic testing among women with a family history of breast cancer. ${ }^{1-4}$ However, significant concerns about genetic testing for breast cancer risk have been raised by professional societies, ${ }^{5-9}$ governmental organizations, ${ }^{10,11}$ and breast cancer patient advocacy groups, ${ }^{12,13}$ all of which call for cautionary and limited use of genetic testing for breast and ovarian cancer susceptibility. Several issues remain unresolved, including the clinical utility of testing, the appropriate setting in which to offer testing, the appropriate candidates for such testing, and the process and content of informed consent.

In a 1996 statement, The American Society of Clinical Oncology (ASCO) recommended that the basic content of informed consent for cancer genetic testing include the implications of positive, negative, or uninformative test results; the implications of testing for other family members; and the risks of psychological distress or genetic discrimination. ${ }^{6} \mathrm{~A}$ subsequent survey of consumers, nurses, and physicians found that those who might make use of breast cancer susceptibility testing would expect a pretest discussion to include much of ASCO's recommended content. ${ }^{14}$ Almost all respondents felt that

\footnotetext{
From the ${ }^{1}$ Cancer Prevention Research Program, Fred Hutchinson Cancer Research Center, Seattle, Washington; ${ }^{2}$ Clinical Genetics Service, Memorial Sloan-Kettering Cancer Center, New York, New York; ${ }^{3}$ Division of Perinatal Medicine, Swedish Medical Center, Seattle, Washington; and ${ }^{4}$ Departments of Medicine and Medical History and Ethics, University of Washington, Seattle, Washington.

Judy L. Hull, MS, Memorial Sloan-Kettering Cancer Center, Clinical Genetics Service, 1275 York Avenue, Box 145, New York, NY 10021.

Received: November 15, 2000.

Accepted: January 4, 2001
}

obtaining written informed consent from the patient should be required for this test. Yet this survey found that consumers, as compared to nurses and physicians, felt that it was significantly less important to understand the implications of a negative result and the potential risk of psychosocial distress associated with the testing process.

In order to offer breast cancer susceptibility testing in accordance with the ASCO guidelines and other nationally recognized guidelines, ${ }^{5-13,15}$ health professionals need considerable knowledge about the diagnosis of hereditary breast/ovarian cancer, the identification of individuals at increased risk, the current recommendations for preventive care for such individuals, and the ethical and psychosocial issues surrounding genetic susceptibility testing. ${ }^{6,16,17}$ Professional societies have addressed the role of their members in cancer genetic testing. The ASCO statement endorsed the role of oncologists in providing cancer risk counseling and testing. ${ }^{6}$ The National Society of Genetic Counselors (NSGC) has advocated a multidisciplinary approach to predisposition genetic testing, including the collaboration of several medical professionals, with a critical role for genetic counselors. ${ }^{8}$ In addition, a survey of women having two first-degree relatives with breast cancer found that the majority of women prefer that pretest education be done by a genetic counselor and post-test counseling be done by an oncologist. Yet the extent to which oncologists and genetics professionals routinely collaborate in the care of their patients who are considering genetic testing is unknown.

Finally, there has been considerable debate about who is an appropriate candidate for genetic testing for breast and ovarian cancer. Professional guidelines have recommended that genetic testing be offered only when an individual has a strong history of cancer or very early onset of disease. For example, in the case of breast cancer genetic testing, ASCO has stated that the probability of detecting a mutation should be at least $10 \%$ 
before testing is offered. ${ }^{6}$ Other groups, including the American college of Medical Genetics (ACMG), have also proposed guidelines for genetic testing, ${ }^{15,18}$ yet no single set of guidelines has been universally adopted by all health care providers and insurance companies.

In order to determine how oncologists are using genetic testing for breast and ovarian cancer risk, a survey was sent to oncologists who treat adult patients in the Pacific Northwest states of Washington, Oregon, Idaho, and Alaska. The survey assessed oncologists' opinions on many unresolved issues surrounding testing and measured the extent to which oncologists are referring their patients to clinical genetic services.

\section{METHODS}

\section{Study population}

The survey mailing list was obtained from the membership directories of the Washington, Oregon, Idaho, and Alaska state medical associations. All physicians listed under the following adult oncology subspecialties were included: medical, hematologic, radiation, gynecological, and surgical. The survey was mailed to 280 oncologists, but 8 surveys were returned by the postal service indicating the address was incorrect and 8 physicians returned the survey indicating they no longer practice oncology. This left a remaining 264 potential respondents.

\section{Survey mailing}

In June of 1997, the four-page survey and return envelope was mailed with a cover letter eliciting their support in the project. Six weeks later, a second mailing was sent to nonrespondents. There was no financial incentive for completing the survey.

\section{Survey questions}

The survey consisted of six categories, which were (in order of appearance): oncology practice, delivery of pre- and posttest information, using genetic testing, education in genetics, contact with genetic counselors, and demographics.

\section{Oncology practice}

The questions in this section asked about the oncologist's practice, with particular emphasis on use of genetic testing. Survey respondents were asked whether they see patients for breast or ovarian cancer in their practice and what family history information is routinely obtained. Respondents were then asked whether they discussed genetic tests for breast and ovarian cancer susceptibility such as the BRCA1 or BRCA2 tests with any of their patients. Those who had discussed testing were asked the outcome of such discussions, including whether genetic testing was ever offered, how many patients had been tested, and whether referrals had been made to other medical specialties for testing. Respondents were then asked whether they had received marketing materials from commercial laboratories that offer cancer-related genetic tests. And finally, survey respondents were asked whether they feel their practice currently had the necessary services and staff to offer genetic testing for cancer susceptibility.

\section{Delivery of pre- and post-test information}

This set of questions asked the respondents to assume that one of their patients wanted to take a genetic test for breast and ovarian cancer susceptibility. The first question asked respondents to choose which health care professional(s) would be considered appropriate to provide pretest information to the patient, among the following: primary care physician, oncologist, genetic counselor, medical geneticist, and a nurse with training in genetic testing. Respondents were also asked what amount of time should be provided to discuss pretest information and whether a formal signed consent is necessary. The survey then presented eight potential topics to be explained as part of the pretest interaction with the patient and four potential topics to be explained as part of the post-test interactions. The respondent was asked to determine the importance of each item on a 6-point Likert scale.

\section{Candidates for genetic testing}

This section presented five clinical scenarios and asked the respondents to determine the likelihood that they would offer their patient cancer susceptibility testing or refer for such testing, on a 6-point Likert scale. Then respondents were also asked whether such testing should be available for prenatal or childhood testing.

\section{Education in genetics}

Respondents were asked to rate their expertise in cancer genetics compared to others in their medical specialty on a 6-point Likert scale. In addition, respondents were asked to respond on a 6-point Likert scale how interested they would be in continuing professional education in cancer genetics.

\section{Contact with genetic counselors}

The respondents were asked whether they have had contact with a genetic counselor regarding issues of cancer predisposition testing. Finally, they were also asked whether they would like their patients who are considering genetic testing to consult with a genetic counselor and the reason for their opinion.

\section{Demographics}

Respondents were asked their age, sex, year of graduation from medical school, and their primary specialty.

\section{Data analysis}

Data were analyzed using the Statistical Program for the Social Sciences (SPSS for Windows, version 9.0). All two-bytwo Chi-square analyses used a level of 0.05 as the criterion for statistical significance. 


\section{RESULTS}

\section{Characteristics of study sample}

Of 264 surveys sent to Pacific Northwest oncologists, 135 were completed and returned for analysis (response rate $51 \%$ ). The mean age of respondents was 47 ( \pm 8 years). The mean year of graduation from medical school was 1976, with a range between 1957 and 1992. Eighty-one percent were male. Respondents identified themselves as working in the following oncology subspecialties: medical (43\%), radiation $(27 \%)$, hematologic (22\%), gynecological (5\%), surgical (2\%), and urological $(1 \%)$. Ninety-eight percent of respondents reported that they treat patients with breast and ovarian cancer.

\section{Family history-taking practices}

Respondents who treat breast and ovarian cancer patients were asked what family history information they routinely obtain. Almost all respondents indicated they obtain each of the following items: breast and ovarian cancer diagnoses in firstdegree relatives (96\%), breast and ovarian cancer diagnoses in second- and third-degree relatives (93\%), ages of onset of breast or ovarian cancer in relatives $(89 \%)$, and other diagnoses of cancer in the family $(88 \%)$.

\section{Genetic testing practices}

The practices of oncologists surrounding genetic testing for breast and ovarian cancer are summarized in Table 1. The majority of respondents (79\%) had discussed genetic testing for breast and ovarian cancer risk with their patients. Yet a minority of respondents (22\%) actually offered BRCA testing directly to their patients, and 16 oncologists $(12 \%)$ stated that at least one of their patients had actually undergone testing. The total number of patients tested among all respondents was 29 .

Respondents were also asked whether and how they refer patients who are interested in pursuing genetic testing for breast cancer risk. Only $16 \%$ of respondents $(N=22)$ indicated they have referred patients to another specialty to consider genetic testing, primarily to medical genetics or genetic counseling (15 respondents). Other referrals were made to medical oncology (four nonmedical oncologist respondents)

\section{Table 1}

Oncologists' practices in genetic testing for breast and ovarian cancer $(n=135)$

\begin{tabular}{lc}
\hline & $\begin{array}{c}\text { Percent of } \\
\text { respondents } \\
\text { responding } \\
\text { affirmatively }\end{array}$ \\
\hline I have discussed genetic testing with my patients & 79 \\
I offered genetic testing to my patients & 22 \\
At least one woman was tested & 12 \\
$\begin{array}{l}\text { I referred my patients to another medical specialty } \\
\text { patients genetic testing }\end{array}$ & 16 \\
I have received marketing materials for genetic testing & 73 \\
\hline
\end{tabular}

and genetics research (two respondents). In addition, 3\% of respondents indicated that they both offered testing themselves and referred to another specialty.

Respondents were asked whether their practice currently has the necessary services and staff to offer genetic testing for cancer susceptibility; 19\% responded "yes," 61\% responded "no," and 20\% were uncertain. Among oncologists who did not indicate they have the necessary services and staff to offer genetic testing, $10 \%$ indicated in the previous question that they had made referrals for testing to another medical specialty. Combining the answers to these two questions yields a total of $29 \%$ of oncologists who are either equipped to offer genetic testing themselves or who have made referrals to other medical specialties for such testing.

Seventy-three percent of respondents indicated they had received marketing materials about cancer genetic testing.

\section{Delivery of pre- and post-test information}

The survey asked respondents to assume that their patient wishes to take a genetic test for breast and ovarian cancer susceptibility. Oncologists were asked which health professionals would be considered appropriate to provide pretest information to the patient (Table 2). Respondents selected these health professionals: primary care physicians (21\%), oncologists (78\%), genetic counselors (84\%), genetics physicians $(72 \%)$, and nurse with training in genetic testings (57\%). Respondents were also given the opportunity to write-in a specialist; one respondent felt a surgeon would also be appropriate to provide pretest information. The mean recommended duration for a pretest information session was $52( \pm 41)$ minutes.

Regarding the specific content items for a discussion prior to offering a patient genetic testing for breast/ovarian cancer risk, respondents were asked to rate the importance of eight concepts on a scale of 1 ("extremely important") to 6 ("not at all important"). In general, respondents found all of these concepts important, with a mean response for seven of the eight concepts between 1 and 2 (1.13-1.71). These concepts are listed in the order of importance, with the percent indicating the concept is extremely important indicated: risk of cancer associated with a positive result $(88 \%)$, risk of cancer associated with a negative result $(78 \%)$; implications of a positive

Table 2

Health professionals considered appropriate to provide information to patients prior to genetic testing $(n=134)$

\begin{tabular}{lc}
\hline Health professional & $\begin{array}{c}\text { Percent considering } \\
\text { health professional } \\
\text { appropriate to provide } \\
\text { pretest information }\end{array}$ \\
\hline Primary care physician & 21 \\
Oncologist & 78 \\
Genetic counselor & 84 \\
Genetics physician & 73 \\
Nurse who has training in genetic testing & 57 \\
\hline
\end{tabular}


result for other family members $(63 \%)$; potential for discrimination if test result is positive (60\%); potential for indeterminate results (58\%); possible depression, anxiety, or guilt as a results of the testing process (57\%); option of risk-reducing surgery with a positive result (50\%); explaining genes, mutations, and inheritance patterns (28\%). The mean response to this final concept which respondents considered the least important was 2.27.

As part of the post-test interaction with the patient, respondents ranked four items on the same scale. Respondents found all of the items important, with a mean response for all four concepts between 1 and 2 (1.05-1.62). These items were listed in the order of importance with the percent indicating that the item is extremely important indicated: providing an in-person consultation with a positive result (96\%); discussing the psychological impact of test results, such as depression, anxiety, and guilt $(62 \%)$; assisting a patient who tested positive in identifying other family members who might benefit from testing (58\%); and providing an in-person consultation with a negative result (57\%).

Sixty-one percent of respondents indicated that a formal signed consent should be obtained before a patient was tested, $19 \%$ did not think a formal signed consent was necessary and $20 \%$ indicated they were uncertain whether one was necessary.

\section{Candidates for genetic testing}

Respondents were provided with five different scenarios of patients with different clinical and family histories. They were asked to indicate how likely they would be to offer genetic testing in each scenario on a scale of 1 to 6 , with 1 indicating they would definitely not offer testing and 6 indicating they would definitely offer testing. Table 3 summarizes these results. In general, respondents were more likely to offer testing to women whose age at diagnosis or family history was suggestive of hereditary breast cancer. Most respondents (81\%) were unlikely to offer genetic testing to a woman based solely on her level of anxiety.

When asked directly whether or not $B R C A$ testing should be available to minor children, $51 \%$ indicated it should not, $11 \%$ indicated it should be made available, and $38 \%$ indicated they were uncertain. When asked whether or not BRCA testing should be available for prenatal diagnosis, $60 \%$ indicated that it should not be available, $4 \%$ thought it should be available and $36 \%$ indicated they were uncertain.

\section{Education in genetics}

Respondents were asked to rate their expertise in cancer genetics as compared to others in their medical specialty. Seventy-six percent indicated they were more knowledgeable. Those who were more knowledgeable were also more likely to indicate that they have the necessary services and staff to offer genetic testing in their practice $(P=0.03)$.

When asked whether they are interested in continuing professional education in cancer genetics, $87 \%$ of respondents indicated they are interested in continuing education. Knowl-
Table 3

Likelihood of oncologists offering genetic testing or referring for such testing $(n=130)$

\begin{tabular}{|c|c|c|}
\hline Potential genetic test candidate & $\begin{array}{l}\text { Mean } \\
\text { rating }^{a}\end{array}$ & $\begin{array}{l}\text { Percent of } \\
\text { respondents likely } \\
\text { to offer test }{ }^{b}\end{array}$ \\
\hline Woman diagnosed with $\mathrm{BC}$ at age 30 & 4.0 & 73 \\
\hline $\begin{array}{l}\text { Healthy woman whose mother was } \\
\text { diagnosed with } \mathrm{BC} \text { at age } 38\end{array}$ & 3.8 & 68 \\
\hline $\begin{array}{l}\text { Healthy woman whose mother was } \\
\text { diagnosed with BC at age } 65\end{array}$ & 2.2 & 8 \\
\hline $\begin{array}{l}\text { Healthy woman whose mother, sister, } \\
\text { and maternal aunt were diagnosed } \\
\text { with } \mathrm{BC} \text { in their } 40 \text { s }\end{array}$ & 4.9 & 91 \\
\hline $\begin{array}{l}\text { Healthy woman with no family history } \\
\text { of BC but with a high level of breast } \\
\text { cancer anxiety }\end{array}$ & 2.3 & 19 \\
\hline
\end{tabular}

edge in cancer genetics and interest in continuing education were strongly correlated $(P=0.001)$.

\section{Contact with genetic counselors}

Respondents were asked whether they had contact with a genetic counselor regarding issues of cancer predisposition testing, and only 41 (30\%) replied "yes." Reasons for interaction included making a referral or discussing specific patients (16 respondents), asking general information or advice (7 respondents), meeting through professional events (8 respondents), developing local cancer genetics programs (3 respondents), and knowing the genetic counselor personally (1 respondent). The remaining 8 oncologists did not indicate their reason for having contact with a genetic counselor.

However, when asked whether they would like their patients who are considering genetic testing to consult with a genetic counselor, 76\% replied "yes," 4\% replied "no," and 19\% were uncertain. The most common reasons oncologists wanted their patients to see a genetic counselor were that they lacked time or expertise, felt a genetic counselor should explain the implications/uncertainties of testing, or because patients would receive up-to-date technical genetics information. The most common reasons oncologists did not want their patients to see genetic counselors or were uncertain were they felt counseling was not necessary in all cases, they felt pretest information should come from a physician, or they were unsure about using genetic testing at all. 


\section{DISCUSSION}

Survey respondents generally showed caution in their use of genetic testing. Oncologists rated all the pre- and post-test content items as very to extremely important. On average, respondents indicated that almost an hour should be provided for pretest counseling. Few were likely to offer genetic testing to a woman based solely on her level of anxiety. Most oncologists wanted their patients considering testing to consult with a genetic counselor and the majority acknowledged that they do not have the necessary services and staff in their practice to offer genetic testing. Only a minority of oncologists have actually offered testing to their patients.

Only a minority of oncologists reported that they either have the necessary services and staff to offer testing or that they have made referrals to other medical specialties. Oncologists may have a significant need for education and referral information, particularly since most of our respondents have discussed testing with patients. Indeed, almost all of our respondents indicated that they are interested in receiving continuing education in cancer genetics.

Most of the pretest counseling information topics which were found to be extremely important by our respondents were also found to be very important in the ASCO position statement on genetic testing, ${ }^{6}$ the ACMG guidelines, ${ }^{15}$ as well as a survey of physicians ${ }^{14}$ and genetic counselors. ${ }^{19}$ Such items included the risk of cancer associated with a positive or negative test, the possibility of psychological sequelae, and the potential for insurance discrimination. Collectively, these data suggest oncologists, geneticists, other physicians, and genetic counselors have similar ideas regarding the importance of various components of a detailed discussion with patients prior to genetic testing. ${ }^{20-23}$ However, our survey identified one difference: while $28 \%$ of our respondents felt explaining genetics concepts such as genes, mutations, and inheritance patterns was extremely important, a survey of genetic counselors found that $97 \%$ always or often discussed inheritance patterns of cancer. ${ }^{19}$ The reasons for this difference are not clear from this survey. However, possibilities for this difference include time limitations, educational differences, or oncologists may not consider a patient's detailed understanding of genetics concepts to be essential for informed decision-making.

Some responses indicate differences between the practice of oncologists and genetic counselors. While almost all respondents felt that providing genetic test results in-person was extremely important, fewer felt that providing negative results in person was extremely important. Yet genetic counselors typically provide all cancer genetic test results in person. ${ }^{8}$ In our survey, only half of oncologists felt that a signed consent form should be required for genetic testing, whereas genetic counselors routinely obtain informed consent before ordering genetic tests on blood samples obtained from their patients. ${ }^{8}$ Since there is very little physical risk associated with $B R C A$ testing and a formal written consent is rarely obtained before blood draws, oncologists may be less likely to feel that obtaining informed consent is important for such testing.
Potential response biases must be considered. Although a $51 \%$ response rate compares favorably with that of other physician surveys, it is possible that those who responded to the survey were more knowledgeable about genetic testing and may had more interest in genetics. Indeed, the majority of respondents reported that they were more knowledgeable in cancer genetics than others in their specialty. In addition, since the survey cover letter was signed by three genetic counselors, those who returned the survey may be more supportive of genetic counseling. Even though all oncologists in our region were surveyed, it would be interesting to obtain a larger sample of oncologists, which may be possible in another geographical region.

Oncologists in our survey clearly support the use of pretest genetic counseling services. Most respondents indicated they would like their patients who are considering testing to consult with a genetic counselor. Yet fewer than one-third of respondents have made contact with a genetic counselor about cancer genetic testing. Our findings indicate that there is a strong need for increased collaboration between the two disciplines, which may enhance the care provided to cancer patients and their at-risk family members. The National Society for Genetic Counselors (http://www.nsgc.org) has recognized this need and has prepared a list of cancer genetic counselors that accept referrals. In addition, other groups maintain such lists, including the National Cancer Institute (http://cancernet.nci.nih.gov/ genesrch.shtml), GeneTests (http://www.genetests.org), and the Pacific Northwest Regional Genetics Group (http://mchneighborhood.ichp.edu/pacnorgg/index.html). Representatives from NSGC have displayed booths at previous ASCO meetings to enhance awareness of genetic counseling services.

This study and others suggest that collaboration would be welcomed by most in each profession and by patients considering genetic testing. ${ }^{14,24}$ In order to facilitate collaboration and referral, perhaps a stronger effort among genetics professionals toward providing oncologists with information regarding their role in the familial cancer risk setting would be useful. For those oncologists who are unsure about the utility of genetic testing in any setting, it may be helpful to clarify the role of the genetics professionals in cancer risk assessment, during which time the risks, benefits, limitations of genetic testing will be discussed. Continued efforts by professional societies including ASCO, ACMG and NSGC to educate their membership are clearly necessary to further such collaborative opportunities.

\section{Acknowledgments}

This project was supported by PacNoRGG, the Pacific Northwest Regional Genetics Group. PacNoRGG is funded by Project 5H46 MC00091-16 from the Maternal and Child Health Bureau (Title V Social Security Act), Health Resources and Services Administration, Department of Health and Human Services. 


\section{References}

1. Lerman C, Daly M, Masny A, Balshem A. Attitudes about genetic testing for breastovarian cancer susceptibility. J Clin Oncol 1994;12:843-850.

2. Lerman C, Seay J, Balshem A, Audrain J. Interest in genetic testing among firstdegree relatives of breast cancer patients. Am J Med Genet 1995;57:385-392.

3. Struewing JP, Lerman C, Kase RG, Giambarresi TR, Tucker MA. Anticipated uptake and impact of genetic testing in hereditary breast and ovarian cancer families. Cancer Epidemiol Biomarkers Prev 1995;4:169-173.

4. Durfy SJ, Bowen DJ, McTiernan A, Sporleder J, Burke W. Attitudes and interest in genetic testing for breast and ovarian cancer susceptibility in diverse groups of women in western Washington. Cancer Epidemiol Biomarkers Prev 1999;8:369-375.

5. Burke W. Points to consider. Caution and counseling advised with BRCA1 and BRCA2 testing, Pacific Northwest Regional Genetics Group. Genet Northwest 1997; $\mathrm{XI}: 1-3$.

6. Garber JE, Offit K, Olopade OI, Fink D, Barbasch A, Barr P, Gleeson RK, Le Stage B. The American Society of Clinical Oncology Position on Genetic Testing. Cancer 1997;80:632-634

7. ACOG. The American College of Obstetricians and Gynecologists' committee opinion. Breast-ovarian cancer screening. Number 176, October 1996. Int J Gynecol Obstet 1997;56:82-83

8. McKinnon WC, Baty BJ, Bennett RL, Magee M, Neufeld-Kaiser WA, Peters KF, Sawyer JC, Schneider KA. Predisposition genetic testing for late-onset disorders in adults: a position paper of the National Society of Genetic Counselors. JAMA 1997; 278:1217-1220

9. ASHG. Statement of the American Society of Human Genetics on genetic testing for breast and ovarian cancer predisposition. Am J Hum Genet 1994;55:i-iv.

10. Pinn VW, Jackson DM. Advisory Committee to NIH Office passes resolutions. J Womens Health 1996;5:549-553.

11. NCHGR. Statement on use of DNA testing for presymptomatic identification of cancer risk. National Advisory Council, National Center for Human Genome Research. JAMA 1994;271:785.

12. NAPBC. Position paper: hereditary susceptibility testing for breast cancer. National Action Plan on Breast Cancer, Hereditary Susceptibility Working Group. Washington DC: National Action Plan on Breast Cancer, 1996.
13. NBCC. Presymptomatic genetic testing for heritable breast cancer risk. Washington DC: The National Breast Cancer Coalition, 1995.

14. Geller G, Bernhardt BA, Doksum T, Helzlsouer KJ, Wilcox P, Holtzman NA. Decision-making about breast cancer susceptibility testing: how similar are the attitudes of physicians, nurse practitioners, and at-risk women? J Clin Oncol 1998;16:28682876.

15. ACMG. Genetic susceptibility to breast and ovarian cancer: assessment, counseling, and testing guidelines. Executive summary of the New York State Department of Health. Am Coll Med Genet 1999.

16. Greene MH. Genetics of breast cancer. Mayo Clin Proc 1997;72:54-65.

17. Lerman C, Narod S, Schulman K, Hughes C, Gomez-Caminero A, Bonney G, Gold K, Trock B, Main D, Lynch J, Fulmore C, Snyder C, Lemon SJ, Conway T, Tonin P, Lenoir G, Lynch H. BRCA1 testing in families with hereditary breast-ovarian cancer: a prospective study of patient decision making and outcomes. JAMA 1996;275: $1885-1892$.

18. Kaiser Permanente. Clinical practice guidelines for referral for genetic counseling for inherited susceptibility for breast and ovarian cancer. 1997:2-3.

19. Schneider KA, Marnane D. Cancer risk counseling. How is it different? J Genet Couns 1997;6:97-109.

20. Biesecker B, Boehnke M, Calzone K, Markel DS, Garber JE, Collins FS, Weber BL. Genetic counseling for families with inherited susceptibility to breast and ovarian cancer. JAMA 1993;269:1970-1974.

21. Lynch HT, Lemon SJ, Durham C, Tinley ST, Connolly C, Lynch JF, Surdam J, Orinion E, Slominski-Caster S, Watson P, Lerman C, Tonin P, Lenoir G, Serova O, Narod S. A descriptive study of BRCA1 testing and reactions to disclosure of test results. Cancer 1997;79:2219-2228.

22. Schneider KA. Counseling about cancer. Strategies for genetic counselors, 2nd Ed Boston: National Society of Genetic Counselors, 1994.

23. Baty BJ, Venne VL, McDonald J, Croyle RT, Halls C, Nash JE, Botkin JR. BRCA testing: genetic counseling protocol development and counseling issues. J Genet Couns 1997;6:223-243.

24. Audrain J, Rimer B, Cella D, Garber J, Peshkin BN, Ellis J, Schildkraut J, Stefanek M, Vogel V, Lerman C. Genetic counseling and testing for breast-ovarian cancer susceptibility: what do women want? J Clin Oncol 1998;16:133-138. 